This item was submitted to Loughborough's Research Repository by the author.

Items in Figshare are protected by copyright, with all rights reserved, unless otherwise indicated.

\title{
In-vitro experimental analysis and numerical study of temperature in bone drilling
}

PLEASE CITE THE PUBLISHED VERSION

http://dx.doi.org/10.3233/THC-151035

\section{PUBLISHER}

(C) The Authors. Published by IOS PRESS

\section{VERSION}

AM (Accepted Manuscript)

\section{PUBLISHER STATEMENT}

This work is made available according to the conditions of the Creative Commons Attribution-NonCommercialNoDerivatives 4.0 International (CC BY-NC-ND 4.0) licence. Full details of this licence are available at: https://creativecommons.org/licenses/by-nc-nd/4.0/

\section{LICENCE}

CC BY-NC-ND 4.0

\section{REPOSITORY RECORD}

Alam, Khurshid, Mushtaq Khan, Riaz Muhammad, Sayyad Zahid Qamar, and Vadim V. Silberschmidt. 2019. "In-vitro Experimental Analysis and Numerical Study of Temperature in Bone Drilling". figshare. https://hdl.handle.net/2134/19840. 


\title{
In-vitro experimental analysis and numerical study of temperature in bone drilling
}

\author{
Khurshid Alam ${ }^{\mathrm{a}, *}$, Mushtaq Khan ${ }^{\mathrm{b}}$, Riaz Muhammad ${ }^{\mathrm{c}}$, Sayyad Zahid Qamar ${ }^{\mathrm{a}}$ and \\ Vadim V. Silberschmidt ${ }^{\mathrm{d}}$ \\ ${ }^{a}$ Department of Mechanical and Industrial Engineering, College of Engineering, Sultan Qaboos \\ University, Muscat, Sultanate of Oman \\ ${ }^{\mathrm{b}}$ School of Mechanical and Manufacturing Engineering, National University of Sciences and \\ Technology, Islamabad, Pakistan \\ ${ }^{\mathrm{c}}$ Department of Mechanical Engineeringm, CECOS University of IT and Emerging Sciences, Pakistan \\ ${ }^{\mathrm{d}}$ Wolfson School of Mechanical and Manufacturing Engineering, Loughborough University, \\ Loughborough, UK
}

Received 28 March 2015

Accepted 24 July 2015

\begin{abstract}
.
BACKGROUND: Bone drilling is a common practice of surgical treatments in orthopaedics and traumatology. Penetration of a high-speed drill into bone tissue is accompanied by generation of a significant amount of heat. Cooling of the drilling region is necessary to avoid potential risk of thermal damage to bone.

OBJECTIVE: The purpose of this study was to measure and predict bone temperature by conducting experiments and numerical simulations using cooling by means of irrigation at two different temperatures.

METHODS: A series of experiments and numerical studies were performed to investigate the effect of cooling conditions on the rise in bone temperature in drilling. The temperature increase in bone was assessed for different drilling speeds and feed rates in the presence irrigation at $5^{\circ} \mathrm{C}$ and $25^{\circ} \mathrm{C}$.

RESULTS: Bone temperature was found to be strongly affected by the drilling parameters and cooling conditions. Irrigation with water at $5{ }^{\circ} \mathrm{C}$ kept bone temperature well below the thermal threshold level.

CONCLUSION: This study strongly recommends the use of irrigation at lower temperature for safe surgical incision.
\end{abstract}

Keywords: Orthopaedic, bone drilling, experimental analysis, FE modelling, thermal necrosis

\section{Introduction}

General orthopaedic and traumatological surgery and dentistry commonly involve cutting of bone. Several mechanical operations such as sawing [1], plane cutting [2] and drilling [3,4] are widely used in bone surgical procedures. Penetration of hard surgical tools may induce mechanical $[5,6]$ and thermal damage [7] in bone, affecting its integrity and strength of fixation. High-speed drilling in bone involves

\footnotetext{
${ }^{*}$ Corresponding author: Khurshid Alam, Department of Mechanical and Industrial Engineering, College of Engineering, Sultan Qaboos University, P.O. Box 33, Al-Khoud 123, Muscat, Sultanate of Oman. Tel.: +968 24143751; Fax: +968 24141316; E-mail:kalam@squ.edu.om.
} 
a complex process of chip formation, which results in elevated temperatures in bone tissue. Thermal osteonecrosis is one of serious consequences of bone-drilling process [7,8]. According to the literature, the average temperature inducing necrosis in bone was between $47^{\circ} \mathrm{C}$ to $70^{\circ} \mathrm{C}$ [7]. Elevated temperature decreases osteoblastic activity and causes dehydration, which may contribute to death of bone cells [7]. Necrotic cells may adversely affect a bond between fixative devices attached to the bone. Recent reviews on bone-drilling process briefly presented mechanics of bone drilling and associated postoperative complications [7,9]. One of the important factors reducing bone temperature during drilling operations is saline irrigation (cooling) [7,10,11]. The use of internal or external cooling with saline solution can also reduce friction between the drill and the drilled bone and helps in keeping the drilling track clear of bone debris and prevents flutes of the drill bit from clogging.

Temperature measurement in bone drilling was a focus of many research studies. Several studies reported thermal data on bone drilling acquired using experiments and numerical simulations. Most of research conducted was experimental, with bone temperature measured using thermocouples [12,13] or infrared thermography [14,15]. In a recent study by the authors [15], temperature in drilling with vibration superimposed on a drill bit was measured using a non-contact method (infrared thermography) without cooling. The study, however, did not investigate a thermal response of the bone to the drilling process by means of numerical simulations. Some recent studies performed numerical modelling to predict a level of temperature rise in conventional bone drilling [10,16]. A comprehensive review of the recent advances in numerical modelling of the bone-cutting process is presented in [17]. Significant variations in experimental thermal data obtained in previous studies were mainly due to the use of different drilling parameters, bone types, data acquisition systems and the use of saline solutions at different operating temperatures. Also, most numerical studies reporting thermal data on bone drilling used properties of bone obtained from various sources available in the literature. Unavailability of consistent data to an expert in the field could not provide adequate understanding necessary to enhance the current state of the procedures. Conflicting results in thermal data on bone drilling necessitate a development of a more realistic approach to obtain reliable results.

A comprehensive analysis of the bone-drilling process using experiments and numerical simulations is important to estimate the thermal threshold level for bone tissue. To the authors' knowledge, studies of temperature in bone drilling with saline solutions at different temperatures were never reported before. Expensive setups, anisotropic properties of bone, complex kinematics involved in the drilling process and limitations of available finite-element (FE) codes prevented researchers from conducting combined experimental and numerical studies of the process. This paper presents experimental analysis and FE simulations used to measure the level of bone temperature in in-vitro drilling in the presence of external irrigation with two different temperatures. The effect of drilling speed and feed rate on bone temperature was measured and discussed.

\section{Materials and methods}

\subsection{Experiments}

Cortical bone excised from a diaphysis of a femoral shaft was used in experiments. Specimens were cleaned from soft tissues attached to the surface. The level of temperature of specimens was measured and found to be approximately $20^{\circ} \mathrm{C}$. Each specimen could accommodate minimum of twenty holes with diameter $4 \mathrm{~mm}$. The experiments were carried out on a three-axis CNC milling machine (Wadkin Machine Tools, UK). The maximum spindle speed of the machine was 10,000 rpm and the feed rate 
$10 \mathrm{~m} / \mathrm{min}$. During experiments, the specimens were hold firmly in a fixture of the milling machine. A Ktype thermocouple (Thermometrics, Northridge, USA) with a wire diameter of $127 \mu \mathrm{m}$ and a response time of $10 \mu \mathrm{s}$ was used. The thermocouple was placed at a depth of approximately $4 \mathrm{~mm}$ from the bone surface, with its bead at a distance of $1 \mathrm{~mm}$ from the drilling track. A thermo-conductive paste (Omega, OT-201-2) was used to ensure rigid placement of the thermocouple in the bone. The tope surface of the hole drilled for a thermocouple was covered with water-resistant paste. The temperature data was acquired using a FMSDL48 (Glasgow, UK) data logger system.

A standard Ø4 $\mathrm{mm}$ twist drill made of steel was used in all experiments. Its cutting-edge and rake angles were measured and found to be $65^{\circ}$ and $20^{\circ}$, respectively. The helix angle of the drill was $23^{\circ}$ and the point angle was $120^{\circ}$. The drilling speed and feed rate were changed from $1000 \mathrm{rpm}$ to $3000 \mathrm{rpm}$ and $30 \mathrm{~mm} / \mathrm{min}$ to $70 \mathrm{~mm} / \mathrm{min}$, respectively. These parameters were chosen since they were widely reported in the literature on drilling of bone $[13,18,19]$. Some research studies used the drilling speed up to $10000 \mathrm{rpm}$ or above in bone-drilling experiments [3,20] but this did not become a common practice. A schematic of the used experimental set up is shown in Fig. 1. The temperature level was measured in experiments when the cutting edges of the drill bit were passing near the bead of the thermocouple. The maximum temperature was observed when the drill approached the thermocouple's location. Each data point in the subsequent plot of experimental results is the average of three consecutive tests with similar drilling conditions. Tape water at two different temperatures $\left(5^{\circ} \mathrm{C}\right.$ and $\left.25^{\circ} \mathrm{C}\right)$ was supplied to the drilling area using a plastic hose; the volume flow rate was kept constant at $200 \mathrm{ml} / \mathrm{min}$.

\subsection{FE modelling}

A fully thermo-mechanically coupled FE model of the bone-drilling process was developed using MSC MARC software. A specimen of cortical bone was modelled as a cylindrical workpiece discretised with some ten thousand tetrahedral elements. The developed FE model comprised the workpiece (bone) and the drill. The bottom of the workpiece was constrained for all degrees of freedom, and the drill was rotated about is longitudinal axis; the feed was applied to the drill. The cooling condition in FE model was introduced as convection on the bone body (workpiece). The ambient temperature was changed according to the temperature of the cooling medium.

Frequent remeshing was used in simulations to avoid convergence issues associated with high deformations in a process zone in cutting. Separate simulations were run to obtain better convergence and smooth contours, varying mesh densities were tried to minimize the total number of elements and nodes for computational efficiency. Eventually, each simulated interval was subdivided into 1,000 time increments of $1.25 \times 10^{-6} \mathrm{~s}$ to achieve convergence. From our initial simulations, the analysis was found to diverge between increments 7 and 10 depending on cutting parameters. Therefore, remeshing was forced after every 5 increments in the work piece and chip volumes, providing generation of a new mesh. Analysis converged for the element's edge length between $0.01 \mathrm{~mm}$ to $0.015 \mathrm{~mm}$. To assess the effect of mesh density on the numerical results, the element's edge length was varied between the prescribed magnitudes. Since the difference in the calculated temperatures was below $2 \%$, elements with a larger edge length $(0.015 \mathrm{~mm})$ were used in simulations for computational efficiency. As the mesh density was controlled by a fixed value of the element's edge length, the number of elements was almost the same in the subsequent remeshing steps. To check the contact stability in the iteration process, the motion of nodes was automatically controlled with regard to their penetration of a surface by a certain amount. Each simulation took about two hours of on an Intel core i7 workstation with $5 \mathrm{GHz}$ and 4 GB RAM.

The bone was considered as isotropic homogeneous material; its physical properties were taken from recent studies on bone cutting $[10,21]$. Tension tests were performed at various strain rates to quantify 
Table 1

Material properties of cortical bone used in drilling simulations

\begin{tabular}{lcc}
\hline Property & Value & Source \\
\hline Effective elastic modulus (GPa) & 20.0 & {$[10,21]$} \\
Thermal conductivity (W/m K) & 0.54 & {$[23]$} \\
Specific heat (J/kg K) & 1260 & {$[23]$} \\
Density $\left(\mathrm{kg} / \mathrm{m}^{3}\right)$ & $2.26 \times 10^{3}$ & {$[24]$} \\
JC parameters (A, B, C, N) & $(50,101,0.03,0.08)$ & {$[22]$} \\
Coefficient of friction & 0.3 & {$[25]$} \\
\hline
\end{tabular}

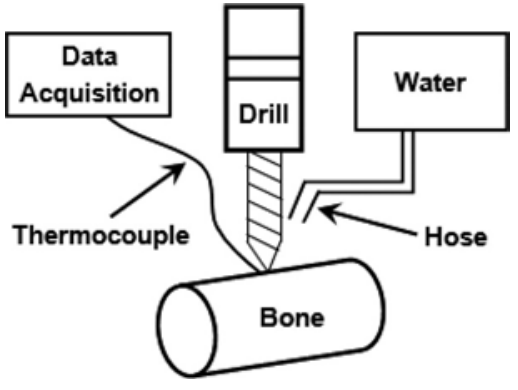

Fig. 1. Schematic of experimental set up for temperature measurements in drilling.

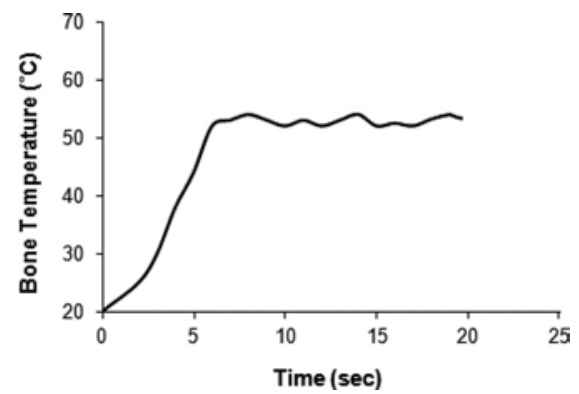

Fig. 2. Temperature evolution in experiments (irrigation temperature $-25^{\circ} \mathrm{C}$, drill speed - $2500 \mathrm{rpm}$, feed rate $-50 \mathrm{~mm} / \mathrm{min}$ ).

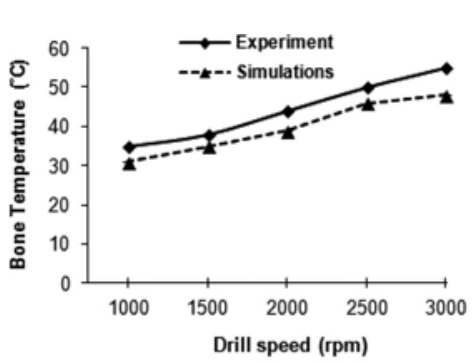

(a)

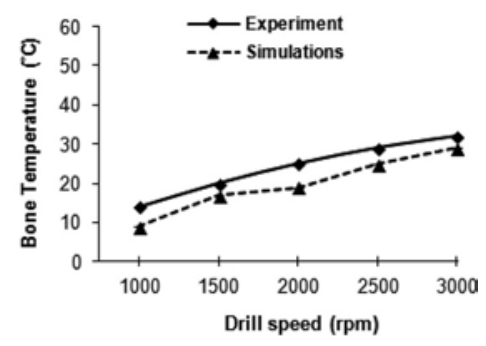

(b)

Fig. 3. Effect of drill speed on bone temperature for different levels of irrigation temperature: (a) $25^{\circ} \mathrm{C}$; (b) $5{ }^{\circ} \mathrm{C}$ (feed rate $-50 \mathrm{~mm} / \mathrm{min}$ ).

a post-yield behaviour and strain rate-sensitivity of cortical bone using dog-bone-shape specimens. The obtained data was used to identify parameters of the Johnson-Cook (JC) material model; details of this procedure are briefly discussed in [22]. Values of thermal conductivity and specific heat of bone were taken from literature; Table 1 shows the properties of cortical bone used in the developed FE model. The drill size, drilling speed and feed rate used in FE simulations were the same as used in experiments. The maximum stress obtained for cortical bone in tension test (140 MPa) was assigned as a criterion for material separation ahead of the drill's cutting edges. The shear-friction model was chosen for simulations.

In numerical simulations, the maximum temperature was noted in the chip location rubbing against the rake of the cutting edges of the drill and, therefore, was not considered in the results. The temperature data for bone around the drill were considered for the same location as that of the thermocouple used in the experiments. The level of temperature in numerical simulations stabilized when the chip was fully developed.

\section{Results}

In experiments, the temperature attained a plateau when the drill passed the thermocouple location. Temperature evolution in bone in experiments is shown in Fig. 2. Two different cooling conditions described earlier were used in experiments and numerical simulations to study the effect of drilling speed on the maximum bone temperature. The feed rate was fixed at the value of $50 \mathrm{~mm} / \mathrm{min}$ to measure 


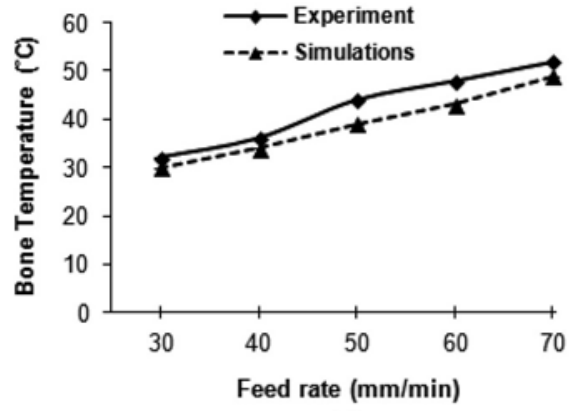

(a)

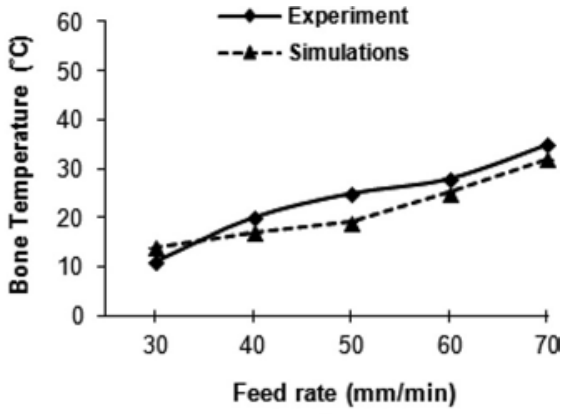

(b)

Fig. 4. Effect of feed rate on bone temperature for different levels of irrigation temperature: (a) $25^{\circ} \mathrm{C}$; (b) $5^{\circ} \mathrm{C}$ (drill speed $2000 \mathrm{rpm})$.

the effect of drilling speed on bone temperature alone. The maximum bone temperature was directly proportional to the drilling speed for both cooling conditions. The influence of drilling speed on bone temperature using two different cooling conditions is shown in Fig. 3. The bone temperature was observed to increase from $35^{\circ} \mathrm{C}$ to $55^{\circ} \mathrm{C}$ when drilling speed was increased from $1000 \mathrm{rpm}$ to $3000 \mathrm{rpm}$ in experiments using irrigation with water at $25^{\circ} \mathrm{C}$. A similar trend was also predicted in numerical simulations. Using water irrigation at $5^{\circ} \mathrm{C}$ in experiments, the bone temperature was increased from $14^{\circ} \mathrm{C}$ to $32{ }^{\circ} \mathrm{C}$ when drilling speed was varied from $1000 \mathrm{rpm}$ to $3000 \mathrm{rpm}$. The temperature dropped by almost $40 \%$ when cooling with $5{ }^{\circ} \mathrm{C}$ was used instead of $25^{\circ} \mathrm{C}$ in experiments as well as in simulations using a drill speed of $3000 \mathrm{rpm}$.

The effect of feed rate on temperature was also studied. The drilling speed was fixed at $2000 \mathrm{rpm}$ to find the effect of feed rate on maximum bone temperature. The temperature was found to vary linearly with the feed rate both in experiments and simulations. The effect of feed rate on bone temperature using two cooling conditions is shown in Fig. 4. The bone temperature was observed to grow from $32{ }^{\circ} \mathrm{C}$ to $52{ }^{\circ} \mathrm{C}$ when the feed rate was increased from $30 \mathrm{~mm} / \mathrm{min}$ to $70 \mathrm{~mm} / \mathrm{min}$ in experiments using irrigation with water at $25^{\circ} \mathrm{C}$. In numerical simulations, using a similar range of feed rate and cooling conditions, the calculated temperature was found to increase from $30^{\circ} \mathrm{C}$ to $49^{\circ} \mathrm{C}$. The temperature dropped by more than $30 \%$ when cooling with $5{ }^{\circ} \mathrm{C}$ was used instead of $25^{\circ} \mathrm{C}$ in experiments as well as in simulations with the highest feed rate used in this study.

The variation of bone temperature with distance away from the cutting lips of the drill along the line perpendicular to the drilling direction was found both experimentally and using simulations for the prescribed cooling conditions. Initially, the bone temperature was measured with thermocouples placed at a distance of $1 \mathrm{~mm}$ from the cutting region in experiments. Then, this distance was increased by intervals of $1 \mathrm{~mm}$ up to a distance of $5 \mathrm{~mm}$ in the subsequent experiments. Temperature values presented in the respective plots of FE results represent average magnitudes of three temperature measurements obtained from different nodes at a distance of $1 \mathrm{~mm}$ from the cutting edges around the drill. The highest value of drilling speed (3000 rpm) was used to find the temperature variation in the bone away from the cutting region. The temperature was found to diminish significantly when the distance from the cutting region was increased as shown in Fig. 5. In simulations, the temperature was calculated at the same distances from the cutting lips of the drill as in experiments in the radial direction. The temperature was calculated when the chips were fully generated and the temperature level stabilized.

Results from analysis of variance (ANOVA) for the experimental data are shown in Table 2. It can be seen from ' $F$ ' and 'p' values that all three factors (drill speed, feed rate, and coolant temperature) have significant effect on bone temperature with coolant temperature being the most significant. 
Table 2

Analysis of Variance (ANOVA) for bone temperature

\begin{tabular}{lrrrrrr}
\hline Source & DF & Seq SS & Adj SS & Adj MS & F & p \\
\hline Drill speed & 4 & 474.38 & 471.75 & 117.94 & 58.24 & 0.000 \\
Feed rate & 4 & 592.67 & 592.67 & 148.17 & 73.17 & 0.000 \\
Water temperature & 1 & 1901.25 & 1901.25 & 1901.25 & 938.89 & 0.000 \\
Error & 10 & 20.25 & 20.25 & 2.03 & & \\
Total & 19 & 2988.55 & & & & \\
\multicolumn{7}{c}{ R-Sq $=99.32 \%$} \\
\hline
\end{tabular}

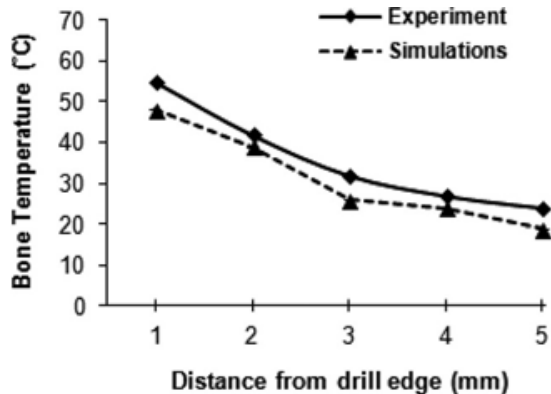

(a)

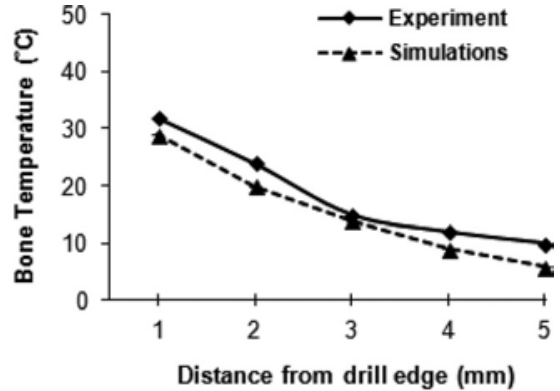

(b)

Fig. 5. Variation of bone temperature away from cutting edge of drill for different levels of irrigation temperature: (a) $25^{\circ} \mathrm{C}$; (b) $5{ }^{\circ} \mathrm{C}$ (drill speed - $3000 \mathrm{rpm}$, feed rate $-50 \mathrm{~mm} / \mathrm{min}$ ).

\section{Discussion}

The temperature predicted in the simulations followed the same trends as those measured in the drilling experiments. The obvious reason for obtaining close results was the use of the same bone used in experiments and acquiring mechanical and thermal data for numerical model. However, some differences between the experimental and numerical results were found, which may be attributed to the remeshing of elements during simulations of the cutting process and inherent errors in experimental measurements. The latter were mainly due to small vibrations in the drilling zone and partial crushing of the thermocouple bead with the bone chips. In machining of materials, the heat generation is proportional to the rate of material deformation. The temperature rise with the increase in the drill speed was caused by the growth of the deformation rate ahead of the cutting edges of the drill. Similarly, the reason for the rise in bone temperature with the growing speed of the drill penetration (feed rate) into the specimen was the rise in the friction between the drill and the bone. The reason behind a significant drop of temperature away from the cutting region was the low heat transport capability of the bone tissue $[23,26]$.

If the lowest value $\left(47^{\circ} \mathrm{C}\right)$ of the threshold temperature for necrosis reported in the literature is considered, then it will occur if the drill speed and feed rate exceed $2000 \mathrm{rpm}$ and $60 \mathrm{~mm} / \mathrm{min}$, respectively, with cooling at $25^{\circ} \mathrm{C}$. On the other hand, if irrigation was performed at $5{ }^{\circ} \mathrm{C}$, the calculated temperatures were found to be well below the necrotic level for all the studied drilling parameters. Cooling the drilling region with water at $5{ }^{\circ} \mathrm{C}$ was sufficient to carry away most of the heat generated at the drill/bone interface and may be the choice for surgeons when drilling hard portions of bones. The results obtained in this study matched the data obtained in other experimental and numerical studies on bone drilling $[10,19,27,28]$.

Much higher levels of bone temperature were measured using infrared thermography when ultrasonic vibrations with frequency above $20 \mathrm{kHz}$ was superimposed on the longitudinal axis of the drill for 
similar drill speed and feed rate [15]. A difference between the results of this study and that presented in [15] was due to different methods used in acquiring thermal data. Measurements of temperature in bone drilling using a thermocouple attached to the cutting edge of the drill provided higher temperatures compared to those where the thermocouple was imbedded in bone [4]. Contrary to the study where the effect of drilling speed and cooling conditions on necrosis penetration in bone material around the drill was studied [10], this study only measured temperature distribution in bone at a specific distance from the drill. Necrosis penetration in bone tissue was observed for drilling speeds above $2500 \mathrm{rpm}$ even in the presence of saline cooling [10].

Temperature measurement in bone drilling is a daunting task. These can explain contradictions among the results presented in various research studies on bone drilling even for the similar drilling conditions and the type of cortical bone. Complex bone microstructure, which varies within a single bone as well as from bone to bone, is one of the reasons for those conflicting results, preventing adequate comparative analysis of results in different studies. It is hoped that advancements in experimental techniques and more reliable material models of bone will supply more precise data in the future.

\section{Limitations of this study}

The effect of cooling at various drilling depths on bone temperature requires further investigations. Due to limited heat transport capability of bone, the drilling temperatures in the presence of cooling need to be measured using non-contact methods such as infrared thermography instead of inserting thermocouples in the bone. However, reliable values of emissivity of the bone tissue will be required for this approach. Besides, this technique is limited to the surface measurements. The used FE model was based on isotropic and homogeneous material properties. A more detailed FE model of the process is needed accounting for mechanical and thermal anisotropy of bone. In addition, the FE model based on temperature-dependent material properties will predict more reliable data of bone temperature in drilling, though the level of temperature changes is moderate. Further studies are suggested to investigate histopathology of bone tissue for drilling speeds in excess of $3000 \mathrm{rpm}$ and feed rate higher than $70 \mathrm{~mm} / \mathrm{min}$ since these parameters are technical requirement in bone drilling.

There is a vast variation of physical properties of bone of various living species. Physical properties of human bones strongly depend on age and sex. Exact measurement of thermal properties of bone, and, hence, its threshold level, is a difficult task. Investigations are still underway to estimate a thermal threshold level for a specific type of bone. All the previous results - including those in this study provided an estimate of this parameter based on the fraction of dead bone cells in a specified region. Exact estimation of the temperature, which may cause bone necrosis, will be the topic of future studies.

The physical properties of bone are strongly linked with its microstructure. It is well documented that porosity of cortical bones ranges between $5 \%$ and $10 \%$. Cortical bone contains various different structures at many scale levels. The level of porosity is due to the resorption cavities, gaps between interlamellar structures and tiny vessels. Such imperfection in the continuous structure of the bone may contribute to the loss of heat transport within bone. This study could not explain the causes behind the variation in bone temperature in experiments related to unique structure of bone and is left for future investigation. One of the ways to explain this variation is to measure the porosity using, e.g. x-ray computed tomography and relate the level of heat transport in bone with porosity.

\section{Conclusion}

Temperature in bone exposed to a drilling procedure was measured and predicted using a series of 
experiments and numerical simulations. Drilling parameters (drill speed and feed rate) and irrigation temperature contributed to variations in bone temperature. The cooling in experiments was performed by supplying water to the drilling region and modelled as a convection heat transfer load on the workpiece (bone) in the developed FE model. The drilling speed above $2000 \mathrm{rpm}$ and the feed rate in excess of $60 \mathrm{~mm} / \mathrm{min}$ were found to be critical drilling parameters for inducing higher temperature in bone in the presence of irrigation at $25^{\circ} \mathrm{C}$. The drilling speed up to $3000 \mathrm{rpm}$ and the feed rate up to $70 \mathrm{~mm} / \mathrm{min}$ can be used for safe drilling in bone with irrigation at temperature of $5^{\circ} \mathrm{C}$. The temperature values predicted in numerical simulations agreed well with the experimental results and may be confidently used in future research to prevent the onset of thermal necrosis and enhance bone surgical procedures.

Lower cost, light weight and manoeuvrability are the factors for using hand-held surgical drills in orthopaedics. Unfortunately, conventional surgical drills have no system to provide feedback about the drill speed, feed rate, drilling force and temperature arising during the process. Surgeons can roughly estimate the feed rate if the depth of drilling and the time to achieve that depth are known. Results of this study can be more useful for clinics using robotical or other advanced surgical systems. Such systems will use a thermal response of the drilled bone to adjust drilling parameters to optimal levels automatically.

\section{References}

[1] James TP, Chang G, Micucci S, Sagar A, Smith EL, Cassidy C. Effect of applied force and blade speed on histopathology of bone during resection by sagittal saw. Med Eng Phys. 2014; 36: 364-370.

[2] Alam K, Khan M, Silberschmidt VV. Analysis of forces in conventional and ultrasonically assisted plane cutting of cortical bone. Proc Inst Mech Eng H. 2013; 227: 636-642.

[3] Lee JE, Rabin Y, Ozdoganlar OB. A new thermal model for bone drilling with applications to orthopaedic surgery. Med Eng Phys. 2011; 33: 1234-1244.

[4] Alam K. Experimental measurements of temperatures in drilling cortical bone using thermocouples. Scientia Iranica, Transactions B: Mechanical Engineering. 2015; 22: 487-492.

[5] Alam K, Kerckhofs G, Mitrofanov AV, Lomov S, Wevers M, Silberschmidt VV. On-line analysis of cracking in cortical bone under wedge penetration. Proc Inst Mech Eng Part H J Eng Med. 2012; 226: 709-717.

[6] Alam K. Experimental and numerical investigation of cracking behavior of cortical bone in cutting. Technol Health Care. 2014; 22: 741-750.

[7] Augustin G, Zigman T, Davila S, Udiljak T, Staroveski T, Brezak D et al. Cortical bone drilling and thermal osteonecrosis. Clin Biomech. 2012; 27: 313-325.

[8] Eriksson AR, Albrektsson T. Temperature threshold levels for heat induced bone tissue injury: a vital-microscopic study in the rabbit. J Prosthet Dent. 1983; 50: 101-107.

[9] Pandey RK, Panda SS. Drilling of bone: A comprehensive review. J Clin Orthop Trauma. 2013; 4: 15-30.

[10] Alam K, Khan M, Silberschmidt VV. 3D finite element modeling of drilling cortical bone: Temperature analysis. J Med Biol Eng. 2014; 34: 618-623.

[11] Benington IC, Biagioni PA, Briggs J, Shearidan S, Lamey PJ. Thermal changes observed at implant sites during internal and external irrigation. Clin Oral Implants Res. 2002; 13: 293-297.

[12] Lee J, Ozdoganlar OB, Rabin Y. An experimental investigation on thermal exposure during bone drilling. Med Eng Phys. 2012; 34: 1510-1520.

[13] Bachus KN, Rondina MT, Hutchinson DT. The effects of drilling force on cortical temperatures and their duration: An in vitro study. Med Eng Phys. 2000; 22: 685-691.

[14] Augustin G, Davila S, Udiljak T, Vedrina DS, Bagatin D. Determination of spatial distribution of increase in bone temperature during drilling by infrared thermography: Preliminary report. Arch Orthop Trauma Surg. 2009; 129: 703709.

[15] Alam K, Silberschmidt VV. Analysis of temperature in conventional and ultrasonically-assisted drilling of cortical bone with infrared thermography. Technol Health Care. 2014; 22: 243-252.

[16] Tu YK, Chen LW, Ciou JS, Hsiao CK, Chen YC. Finite element simulations of bone temperature rise during bone drilling based on a bone analog. J Med Biol Eng. 2013; 33: 269-274.

[17] Marco M, Rodriguez-Millan M, Santiuste C, Giner E, Miguelez MH. A review on recent advances in numerical modeling of bone cutting. Review Article. J Mech Behav Biomed Mater. 2015; 44: 179-201. 
[18] Alam K, Mitrofanov AV, Silberschmidt VV. Experimental investigations of forces and torque in conventional and ultrasonically-assisted drilling of cortical bone. Med Eng Phys. 2011; 33: 234-239.

[19] Hillery MT, Shuaib I. Temperature effects in the drilling of human and bovine bone. J Mater Process Tech. 1999; 92-93: 302-308.

[20] Abouzgia MB, James DF. Temperature rise during drilling through bone. Int J Oral Maxillofac Imp. 1997; 12: 342-353.

[21] Alam K, Mitrofanov AV, Bäker M, Silberschmidt VV. Stresses in ultrasonically assisted bone cutting. J Phys Conf Ser. 2009181 012014 [doi:10.1088/1742-6596/181/1/012014].

[22] Alam K. Experimental and numerical analysis of conventional and ultrasonically-assisted cutting of cortical bone. $\mathrm{PhD}$ thesis. Loughborough University, UK, 2009.

[23] Davidson SR, James DF. Measurement of thermal conductivity of bovine cortical bone. Med Eng Phys. 2000; 22: 741747.

[24] Huiskes J. Some fundamental aspects of human joint replacement. Analyses of stresses and heat conduction in boneprosthesis structures. Acta Orthop Scand. Suppl. 1980; 185: 1-208.

[25] Mellal A, Wiskot HW, Botsis J, Scherrer SS, Belser UC. Stimulating effect of implant loading on surrounding bone. Comparison of three numerical models and validation by in vivo data. Clin Oral Implants. Res. 2004; 15: 239-248.

[26] Biyikli S, Modest MF, Tarr R. Measurements of thermal properties for human femora. J Biomed Mat Res. 1986; 20: 1335-1345.

[27] Mathews LS, Green CA, Goldstein SA. The thermal effects of skeletal flxation pin insertion in bone. J Bone Joint Surg. 1984; 66: 1077-1083.

[28] Augustin G, Davila S, Mihoci K, Udiljak T, Vedrina DS, Antabak A. Thermal osteonecrosis and bone drilling parameters revisited. Arch Orthop Trauma Surg. 2008; 128: 71-77. 